\title{
Abnormalities of vascular endothelial function may contribute to increased coronary heart disease risk in UK Indian Asians
}

\author{
J C Chambers, A McGregor, J Jean-Marie, J S Kooner
}

\begin{abstract}
Objective-To test the hypothesis that abnormalities of endothelial function are present in Indian Asians and may contribute to their increased coronary heart disease risk.

Setting-Single centre in west London. Patients-26 Indian Asian and 18 European white healthy male subjects, aged 35 to 61 years recruited from general practice lists.

Design-Brachial artery diameter responses to reactive hyperaemia and sublingual glyceryl trinitrate were compared using high resolution ultrasound.

Results-Mean (SEM) flow mediated, endothelium dependent dilatation was reduced in Indian Asians compared with European whites, at $3.2(0.8) \% \quad v \quad 5.9$ $(1.0) \%, p=0.03$. In contrast, there were no significant differences in baseline brachial arterial diameter $(4.6(0.1) v 4.6(0.1)$ $\mathrm{mm}, \mathrm{p}=\mathbf{0 . 6 5 )}$ or glyceryl trinitrate induced dilatation $(18.8 \quad(1.5) \% \quad v \quad 18.5$ $(1.7) \%, p=0.90)$ between Indian Asians and European whites, respectively. Univariate analysis showed that Indian Asian race was significantly associated with impaired flow mediated dilatation (regression coefficient $=-2.8 \quad(1.3) \%$, $\mathbf{p}=\mathbf{0 . 0 3}$ ), and in multivariate analysis, this relation was independent of both conventional coronary heart disease risk factors and markers of insulin resistance. Conclusions-Endothelial function is impaired in healthy UK Indian Asians compared with European whites, and the defect is not accounted for by major coronary heart disease risk factors. Endothelial function may be modulated by novel risk factors in Indian Asians.

(Heart 1999;81:501-504)
\end{abstract}

Keywords: endothelial function; Indian Asians; coronary heart disease; risk factors

Premature coronary heart disease mortality is higher in UK Indian Asians than in European whites. ${ }^{1}$ Increased mortality in Indian Asians is particularly striking in men aged 30 to 39 years in whom the relative risk of death from coronary heart disease is 2 , and in men aged 20 to 29 whose relative risk is 3, compared with age matched European whites. ${ }^{1}$ The reasons underlying the excess coronary heart disease risk in Indian Asians are not known. Conventional risk factors-including smoking, hypercholes- terolaemia, and hypertension-have a lower prevalence in Indian Asians compared with European whites, ${ }^{2}$ and do not account for the higher cardiovascular mortality. ${ }^{3}$ The prevalence of diabetes ${ }^{4}$ and of insulin resistance ${ }^{3}$ is higher in Indian Asians than in European whites, although the mechanisms linking these disorders to coronary heart disease are not well understood.

We hypothesised that abnormalities of vascular endothelial function are present in Indian Asians and may contribute to their increased coronary heart disease risk. Previous studies have used biochemical markers to assess endothelial function. However, impaired endothelium dependent dilatation is a sensitive marker of endothelial dysfunction, which occurs early during development of atherosclerosis, and improves during regression of the atherosclerotic lesion. ${ }^{56}$ In this study we measured brachial artery endothelium dependent dilatation using high resolution ultrasound to assess endothelial function in healthy Indian Asians and European whites.

\section{Methods}

SUBJECTS

We identified 50 Punjabi Sikh (Indian Asian) and 50 European white male subjects aged 35 to 60 years, who were not known to have hypertension, diabetes, hypercholesterolaemia, or to be cigarette smokers, from the practice lists of five local general practitioners. Punjabi Sikhs were selected to represent Indian Asians as they are a culturally discrete and ethnically homogeneous group who also form the largest Indian Asian subgroup in the London Borough of Ealing. In response to a postal invitation, 28 Indian Asians and 25 British whites agreed to take part in the study. When subjects attended for investigation, nine subjects (two Indian Asian and seven British white) were found to be have one or more of the prospectively defined exclusion criteria. These subjects were excluded from the study.

We therefore studied 26 Indian Asian and 18 European white subjects, providing a 90\% power to detect a difference of $2 \%$ in mean flow mediated dilatation between the two groups at the $5 \%$ significance level. None was taking cardiovascular drugs.

Local ethics committee approval was obtained and all subjects gave informed consent to participate. All Indian Asians had been born overseas and were resident in the United Kingdom for a mean of 27 years (range 17 to 40 ). 
Table 1 Clinical and biochemical characteristics of subjects

\begin{tabular}{llll}
\hline & $\begin{array}{l}\text { European whites } \\
(n=18)\end{array}$ & $\begin{array}{l}\text { Indian Asians } \\
(n=26)\end{array}$ & $p$ Value \\
\hline Age (years) & $45.8(35$ to 61$)$ & $46.7(35$ to 60$)$ & 0.64 \\
Body mass index $\left(\mathrm{kg} / \mathrm{m}^{2}\right)$ & $27.2(0.9)$ & $27.7(0.9)$ & 0.55 \\
Waist/hip ratio & $0.94(0.02)$ & $0.99(0.01)$ & 0.03 \\
Systolic blood pressure (mm Hg) & $127(3)$ & $125(3)$ & 0.7 \\
Diastolic blood pressure (mm Hg) & $81(2)$ & $79(2)$ & 0.44 \\
Total cholesterol (mmol/1) & $5.7(0.2)$ & $5.7(0.2)$ & 0.94 \\
HDL cholesterol (mmol/l) & $1.21(0.05)$ & $0.91(0.04)$ & $<0.01$ \\
Triglycerides (mmol/l) & $1.5(0.1)$ & $1.9(0.2)$ & 0.15 \\
Fasting blood glucose (mmol/l) & $5.1(0.1)$ & $5.8(0.1)$ & $<0.01$ \\
Fasting insulin (mU/l) & $7.3(0.6)$ & $13.8(1.0)$ & $<0.01$ \\
HOMA-R (U) & $1.7(0.1)$ & $3.6(0.3)$ & $<0.01$ \\
Baseline brachial diameter (mm) & $4.6(0.1)$ & $4.6(0.1)$ & 0.65 \\
\hline
\end{tabular}

Data are means (range or SEM).

HDL, high density lipoprotein; HOMO-R, homeostasis model insulin resistance index.

CLINICAL AND BIOCHEMICAL CHARACTERISATION Medical history, past and family history of hypertension and diabetes, and smoking habit were recorded in all subjects. Three blood pressure readings were taken by mercury sphygmomanometer, with the subject seated for 10 minutes. Anthropometric measurements (height, weight, waist-hip girth ratio) and resting 12 lead electrocardiogram were recorded by standardised protocols. Body mass index (BMI) was calculated as weight ( $\mathrm{kg}$ ) divided by height squared $\left(\mathrm{m}^{2}\right)$. Subjects were studied after an overnight fast. Blood samples were collected for plasma glucose, total cholesterol, high density lipoprotein (HDL) cholesterol, and triglyceride determinations (Beckman CX7 analyser). Plasma insulin was measured by coated tube immunoassay (Enzymun-test, Boehringher Mannheim, Mannheim, Germany), and the homeostasis model insulin resistance index (HOMA-R; Units, U) was calculated (fasting glucose $[\mathrm{mmol} / \mathrm{l}] \times$ fasting insulin $[\mathrm{mU} / 1] / 22.5)$ for assessment of insulin sensitivity. $^{7}$

BRACHIAL ARTERY DIAMETER

Brachial artery flow mediated dilatation was measured using a $7.0 \mathrm{MHz}$ linear array transducer, an Acuson $128 \mathrm{XP} / 10$ system (Mountain View, California, USA), and high resolution ultrasonic vessel wall tracking system (Vadirec, Ingenious Systems, the Netherlands), as described by Celermajer et al. ${ }^{8}$ The brachial artery was scanned longitudinally, $5-10 \mathrm{~cm}$ above the elbow, until clear signals were obtained from the anterior and posterior walls. A stereotactic clamp was used to hold the transducer in the same position throughout the procedure. The images were magnified by a resolution box function and measurements taken from the anterior to posterior " $\mathrm{m}$ " line at end diastole, using the $\mathrm{R}$ wave on the electrocardiogram. Brachial artery diameter was measured by identifying a clear section of the vessel on $B$ mode. The $M$ mode cursor was then placed over this point at right angles to the vessel wall. A five second segment of the A mode signal was then routed to the wall tracking system designed to track vessel wall movement on a beat to beat basis. After the baseline resting scan, a pneumatic cuff placed at the level of the wrist was inflated to $300 \mathrm{~mm} \mathrm{Hg}$ for 4.5 minutes. The second scan was performed 55-65 seconds after cuff deflation. Fifteen minutes were allowed for vessel recovery, after which the second baseline scan was performed. Glyceryl trinitrate $(400 \mu \mathrm{g})$ was then given and the fourth scan of the brachial artery undertaken.

Studies were analysed by two independent observers, blinded to the patient's stage of investigation. The technique for measurement of brachial artery flow mediated dilatation is reproducible in our laboratory. There is a close correlation between the observers for brachial artery measurements (diameter 0.99 , dilatation 0.90). The coefficient of variation for flow mediated dilatation is $2 \%$, based on measurements taken from the same subjects, on separate days, under resting conditions. This compares favourably with other centres. ${ }^{9}$ Flow mediated dilatation of conduit arteries has been shown to be endothelium dependent and largely mediated by nitric oxide. ${ }^{10}$

DATA PROCESSING AND ANALYSIS

Data were analysed using the Stata Release 5 statistical package. Continuous data were expressed as mean (SEM). The ShapiroFrancia 'W' test and Bartlett's test were applied to confirm normality and equality of variances, respectively. After log transformation if necessary, the independent samples $t$ test was used to compare the mean values of flow mediated dilatation as well as other variables between the two study groups. Following this, univariate and multiple linear regression analyses were conducted with flow mediated dilatation as the primary dependent. Statistical significance was inferred at a $\mathrm{p}$ value of $<0.05$.

\section{Results}

CLINICAL AND BIOCHEMICAL CHARACTERISTICS Clinical and biochemical measurements for the two groups are summarised in table 1. There were no significant differences in age, body mass index, systolic or diastolic blood pressure, total cholesterol, or triglycerides between the groups. However, in comparison to European whites, Indian Asians had higher fasting

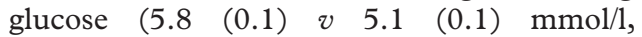
$\mathrm{p}<0.01)$, higher fasting insulin $(13.8(1.0) v$ $7.3(0.6) \mu \mathrm{U} / \mathrm{ml}, \mathrm{p}<0.01)$, higher HOMA-R (3.6 (0.3) v $1.7(0.1) \mathrm{U}, \mathrm{p}<0.01)$, higher waist-hip ratio $(0.99(0.01) v 0.94$ (0.02), $\mathrm{p}=0.03)$, and lower HDL cholesterol (1.01 (0.04) v $1.21(0.05) \mathrm{mmol} / \mathrm{l}, \mathrm{p}<0.01)$.

BRACHIAL ARTERY FLOW MEDIATED DILATATION Flow mediated, endothelium dependent dilatation was reduced in Indian Asians compared with European whites (3.2 (0.8)\% v 5.9 $(1.0) \%, p=0.03$ ) (fig 1). In contrast, there were no significant differences in baseline brachial arterial diameter between Indian Asian and European white subjects (4.6 (0.1) $v 4.6$ $(0.1) \mathrm{mm}, \mathrm{p}=0.65)$ or in brachial artery dilatation in response to sublingual glyceryl trinitrate $(18.8 \quad(1.5) \% \quad v \quad 18.5 \quad(1.7) \%$, $\mathrm{p}=0.90)$.

UNIVARIATE AND MULTIVARIATE ANALYSIS

In univariate regression analysis, Indian Asian race was significantly associated with flow 

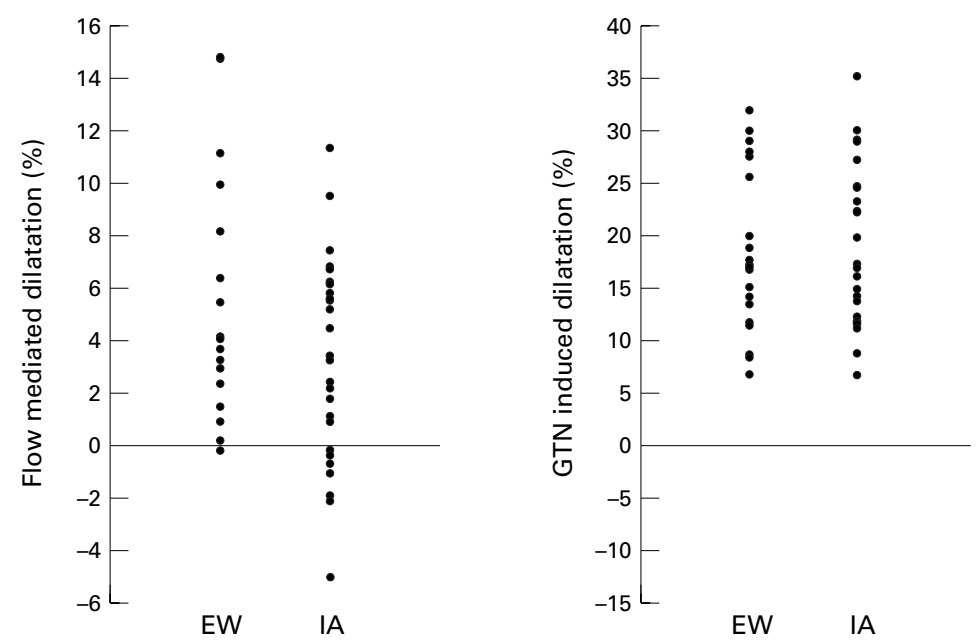

Figure 1 Flow mediated and glyceryl trinitrate (GTN) induced dilatation in Indian Asians (IA) and European whites $(E W)$.

Table 2 Multivariate regression analysis for determinants of flow mediated dilatation

\begin{tabular}{lll}
\hline & $\begin{array}{l}\text { Partial regression coefficient } \\
\text { (mean }(\text { SEM)) }\end{array}$ & p Value \\
\hline Indian Asian race (\%) & $-40.3(19.6)$ & 0.05 \\
Age $(\% /$ years) & $-0.24(0.12)$ & 0.05 \\
Waist/hip ratio (\%) & $-29.9(15.6)$ & 0.07 \\
Systolic blood pressure $(\% / \mathrm{mm} \mathrm{Hg})$ & $0.0(0.1)$ & 0.65 \\
Diastolic blood pressure $(\% / \mathrm{mm} \mathrm{Hg})$ & $-0.1(0.1)$ & 0.46 \\
Total cholesterol $(\% .1 / \mathrm{mmol})$ & $0.2(0.8)$ & 0.84 \\
HDL cholesterol $(\% .1 / \mathrm{mmol})$ & $3.8(4.3)$ & 0.38 \\
Triglycerides $(\% .1 / \mathrm{mmol})$ & $-0.8(1.8)$ & 0.68 \\
Glucose $(\% .1 / \mathrm{mmol})$ & $-0.5(1.2)$ & 0.13 \\
HOMA-R $(\% / \mathrm{U})$ & $-0.1(2.5)$ & 0.97 \\
Baseline brachial diameter $(\% / \mathrm{mm})$ & $-0.5(1.2)$ & 0.66 \\
\hline
\end{tabular}

HDL, high density lipoprotein; HOMO-R, homeostasis model insulin resistance index.

mediated dilatation (regression coefficient $(R)=-2.8$ (1.3)\%, p = 0.03), HDL cholesterol $(R=-0.20(0.06) \% .1 / \mathrm{mmol}, \mathrm{p}<0.01)$, HOMA-R $(R=1.89(0.40) \% / \mathrm{U}, \mathrm{p}<0.01)$, and waist-hip ratio $(R=0.05 \quad(0.02) \%$, $\mathrm{p}=0.03$ ), but not with total cholesterol, triglycerides, or blood pressure. On multiple regression analysis, Indian Asian race remained significantly correlated with flow mediated dilatation (partial regression coefficient $=-40.3(19.6) \%, p=0.05)$, independent of HDL cholesterol, HOMA-R, waist-hip ratio, age, blood glucose, total cholesterol, triglycerides, and baseline brachial arterial diameter (table 2).

\section{Discussion}

The major findings of this study are that brachial artery vascular endothelial function is impaired in healthy UK Indian Asians compared with European whites, and that this difference cannot be attributed to major risk factors for atherosclerosis.

Previous studies have shown that brachial artery flow mediated dilatation is endothelium dependent, mediated largely by the release of nitric oxide from the endothelium, ${ }^{11}$ and inhibited by L-NMMA, ${ }^{10}$ the competitive inhibitor of nitric oxide production. A close correlation exists between brachial artery flow mediated dilatation and coronary artery endothelium dependent vasomotor responses. ${ }^{12}$ Our findings of impaired brachial artery flow mediated dilatation in healthy Indian Asians suggest that endothelial nitric oxide activity is reduced in Indian Asians compared with European whites. Vascular endothelial nitric oxide plays an important role in maintaining vascular integrity by modulating vascular tone, inhibiting thrombosis and leucocyte adhesion, and by influencing proliferation of smooth muscle cells in the arterial wall. ${ }^{13}$ Reduced levels of endothelial nitric oxide in Indian Asians may contribute to vascular injury and disease by facilitating platelet-vascular wall interactions, adhesion of circulating monocytes to the endothelial surface, and vascular smooth muscle proliferation.

In this study, racial differences in endothelial function were not accounted for by differences in age, hypertension, hypercholesterolaemia, or cigarette smoking between the groups. ${ }^{14-16}$ This is consistent with the epidemiological data which have shown that the higher coronary heart disease mortality in UK Indian Asians than European whites ${ }^{1}$ cannot be explained by these conventional coronary heart disease risk factors. $^{23}$ The prevalence of diabetes ${ }^{4}$ and of insulin resistance ${ }^{3}$ is higher in Indian Asians than in European whites and may account for part of the increased coronary heart disease risk in Indian Asians. ${ }^{23}$ We used the HOMA-R index, which is closely correlated with the hyperinsulinaemic-euglycaemic clamp technique, as a measure of insulin sensitivity. ${ }^{77}$ Compared with European whites, Indian Asians had reduced insulin sensitivity, lower HDL cholesterol, and higher waist-hip girth ratio, confirming the existence of impaired insulin action in Indian Asians. ${ }^{318}$ However, in multivariate analysis, the relation between Indian Asian race and flow mediated dilatation was independent of insulin resistance and its associated metabolic defects. Although there are limitations in studying small numbers, our observations raise the possibility that genetic or other novel coronary heart disease risk factors may modulate endothelial function among Indian Asians. Our observations of impaired endothelial function in Indian Asians compared with European whites contrast with preserved endothelial function in the Chinese, whose risk of coronary heart disease is lower than in European whites.

\section{CONCLUSIONS}

In summary, we have shown that endothelial function is impaired in Indian Asians compared with European whites, and that this defect is not accounted for by the major coronary heart disease risk factors. Genetic or other novel risk factors may modulate endothelial function in Indian Asians, who are susceptible to coronary heart disease. ${ }^{19} 20$

We are grateful to Michael Kemp for the biochemical analyses and to Donna Hammal and Caroline Doré for statistical analyses.

1 Balarajan R. Ethnicity and variations in mortality from coronary heart disease. Health Trends 1996;28:45-51.

2 McKeigue PM, Ferrie JE, Pierpoint T, et al. Association of early-onset coronary heart disease in South Asian men with glucose intolerance and hyperinsulinemia. Circulation
1993;87:152-61. 
3 McKeigue PM, Shah B, Marmot MG. Relation of central obesity and insulin resistance with high diabetes prevalence 382-6.

4 Mather HM, Keen H. The Southall diabetes survey: prevalence of known diabetes in Asians and Europeans. BMF 1985;291:1081-4.

5 Benzuly KH, Padgett RC, Kaul S, et al. Functional improvement precedes structural regression of atherosclerosis. Circulation 1994;89:1810-18.

6 Harrison DG, Armstrong ML, Freiman PC, et al. Restoration of endothelium-dependent relaxation by dietary treatment of atherosclerosis. F Clin Invest 1987;80:1808-11.

7 Nagasaka S, Iwamoto Y, Ishikawa S, et al. Efficacy of troglitazone measured by insulin resistance index. Lancet 1997;350:184.

8 Celermajer DS, Adams MR, Clarkson P, et al. Passive smoking and impaired endothelium-dependent arterial dilatation in healthy young adults. $N$ Engl $\mathcal{F}$ Med 1996;334: 150-4.

9 Leeson P, Thorne S, Donald A, et al. Non-invasive measurement of endothelial function: effect on brachial artery dilation of graded endothelial dependent and

10 Joannides R, Haefeli WE, Linder L, et al. Nitric oxide is responsible for flow-dependent dilatation of human peripheral conduit arteries in vivo. Circulation 1995;91:1314-19.

11 Clarkson P, Adams MR, Powe AJ, et al. Oral L-arginine improves endothelium-dependent dilation in hypercholesterolemic young adults. $\mathcal{F}$ Clin Invest 1996;97:1989-94.

12 Anderson TJ, Uehata A, Gerhard MD, et al. Close relation of endothelial function in the human coronary and peripheral circulations. F Am Coll Cardiol 1995;26:1235-41.
13 Vane JR, Anggard EE, Botting RM. Regulatory functions of the vascular endothelium. N Engl f Med 1990;323:27-36.

14 Celermajer DS, Sorensen KE, Spiegelhalter DJ, et al. Aging is associated with endothelial dysfunction in healthy men years before the age-related decline in women. $f \mathrm{Am}$ Coll Cardiol 1994;24:471-6.

15 Panza JA, Casino PR, Kilcoyne CM, et al. Impaired endothelium-dependent vasodilation in patients with essential hypertension: evidence that the abnormality is not at the muscarinic receptor level. $\mathcal{F}$ Am Coll Cardiol 1994;23: the muscari

16 Sorensen KE, Celermajer DS, Georgakopoulos D, et al. Impairment of endothelium-dependent dilation is an early event in children with familial hypercholesterolemia and is related to the lipoprotein(a) level. F Clin Invest 1994;93:505.

17 Matthews DR, Hosker JP, Rudenski AS, et al. Homeostasis model assessment: insulin resistance and beta-cell function from fasting plasma glucose and insulin concentrations in man. Diabetologia 1985;28:412-19.

18 Kooner JS, Baliga RR, Wilding J, et al. Abdominal obesity, impaired non-esterified fatty acid suppression, and insulinmediated glucose disposal are early metabolic abnormalities in families with premature myocardial infarction. Arterioscler Thromb 1998;18:1021-6.

19 Woo KS, McCrohon JA, Chook P, et al. Chinese adults are less susceptible than whites to age-related endothelial dysfunction. $\mathcal{A}$ Am Coll Cardiol 1997;30:113-18.

20 Woo KS, Robinson JT, Chook P, et al. Differences in the effect of cigarette smoking on endothelial function in Chinese and white adults. Ann Intern Med 1997;127:372-5. 